\title{
XLVI. Remarks on certain proposed improvements in the magneto-electric machine
}

\author{
Rev. William Ritchie LL.D. F.R.S.
}

To cite this article: Rev. William Ritchie LL.D. F.R.S. (1836) XLVI. Remarks on certain proposed improvements in the magneto-electric machine, Philosophical Magazine Series 3, 9:53, 222-223, DOI: $10.1080 / 14786443608636481$

To link to this article: http://dx.doi.org/10.1080/14786443608636481

册 Published online: 01 Jun 2009.

Submit your article to this journal $₫$

Џ Article views: 2

Q View related articles $\asymp$ 
from the reaction of the armature: and the density also of the armature has considerable influence over its inducing power, both on the steel magnet and the electro-magnet; if the armature applied to the electro-magnet be made of very hard steel, it will not sustain so much weight from the same intensity of galvanic current as if it be made of soft iron.

Thus it will be obvious that the more the steel is allied to iron in its temper, the more closely the effect of the keeper upon the steel magnet will resemble that upon the electromagnet. Hence the explanation of the action of the armature upon the one will apply to the other.

In order that no misconception of my meaning may take place, I will give one application of the above reasoning to the case of the electro-magnet. Suppose a feeble galvanic current to have been passed around an electro-magnet, and that the magnetism induced by this current is represented by $a$ and $b$; then, according to the foregoing explanation, $2 a$ and $2 b$ will represent the magnetism on each side of the centre of the armature; and as this exceeds the magnetic power induced by the voltaic helix in the electro-magnet by $a+b$, the armature will induce $a+b$ of magnetism in the electro-magnet. As soft iron offers so little impediment to the inducing power of the armature, this power may be considered to exert its maximum effect upon very soft iron, and its minimum on the hardest steel: now suppose the electro-magnet to have received an accession of magnetism from a stronger galvanic current, which may be represented by $c+d$, then the inducing power of the armature will be raised to $2(b+d)$ at one extremity, and $2(a+c)$ at the other; and the electro-magnet will have now received from the armature $c+d$ more of magnetism, and so on for all future additions of magnetism induced by the voltaic helix, until the electro-magnet has attained the highest state of magnetism it is capable of.

XLVI. Remarks on certain proposed Improvements in the Magneto-Electric Machine. By the Rev. William Ritchie, LL.D., F.R.S., Professor of Natural Philosophy in the Royal Institution of Great Britain and in the University of London.

T $\mathrm{N}$ the last Number of the Philosophical Magazine, p. 120 , there is a paper on Magneto-electric Machines, by Fred. Mullins, Esq., M.P., of such an extraordinary nature, that $I$ feel myself called upon to point out its fallacy and inconsistency. As facts are by far the most stubborn things to get rid of, I shall simply state two experiments, which will be quite sufficient, without entering at all into the principles of the science. 
Experiment 1. Take two bars of soft steel of any convenient size, cut one of them in the middle, and bend the other into the form of a horse-shoe magnet; temper both to the same colour, magnetize them equally, and try their powers in the following manner: bring the two bars, as in the figure, to different distances from the lifter $A B$, and ascertain their attractive power; remove the bars and substitute the horse-shoe, and its power of

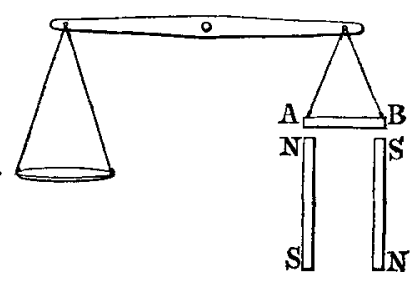
attraction, and consequently its inducing power, will be found to be much superior. Place the bars and horse-shoe in succession at the same distance from a revolving lifter, and the electricity induced on the coil will be found to be much greater, both in deflecting a needle and in decomposing water, with the horse-shoe magnet than with the equal bars.

Hence the absurdity of using bar magnets instead of horseshoe ones to induce magnetism on soft iron, and thence voltaic electricity on a coil.

Experiment 2. Cut a bar of the same length as before into three portions, bend one of the pieces into an arc, magnetize the two parts, apply the arc to form a horse-shoe magnet as Mr. Mullins proposes, repeat the previous experiment, and the old horse-shoe magnet will be found to be much stronger than the new one.

It is easy to see how Mr. Mullins, in his experimental researches, has been led into these errors. Horse-shoe magnets, made by ignorant makers, are often left almost entirely soft at the bending and only hardened towards the poles or ends, from the old absurd notion that the magnetism was accumulated at the poles. The soft part of the circuit therefore, possessing scarcely any coercitive power, is very much in the same state with a piece of soft iron. Such a magnet may perhaps be improved by cutting off the bending and supplying its place by a properly magnetized arc. Another error into which Mr. Mullins has fallen is not so easily accounted for: he affirms that the size of the arc is of no consequence. A tempered steel wire would therefore be as good as an arc formed of steel, two inches broad and half an inch thick. Instead then of recommending gentlemen who have horse-shoe magnets applied to magneto-electric machines, to cut off the bending, the wisest course will be to let them alone if they are properly tempered, if not, to get them re-tempered and remagnetized. 